\title{
GREENVEC GAME FOR SKIN CONDUCTIVITY LEVEL (SCL) BIOFEEDBACK PERFORMANCE SIMULATOR USING GALVANIC SKIN RESPONSE (GSR) SENSOR
}

\author{
A.Noraziah', Muhd Azrulnizam Suna Abdullah', Nurzety Aqtar ${ }^{1}$, \\ MohammedAdam Ibrahim Fakhreldin ${ }^{1}$ and Muhammad Nubli Abd Wahab ${ }^{2}$ \\ ${ }^{1}$ Faculty of Computer Systems \& Software Engineering, Universiti Malaysia Pahang, \\ 26300 Gambang, Pahang, Malaysia \\ ${ }^{2}$ Center of Modern Language and Human Sciences, \\ Universiti Malaysia Pahang, LebuhrayaTunRazak, 26300 Gambang, Kuantan, Pahang, \\ Malaysia \\ Email: noraziah@ump.edu.my
}

\begin{abstract}
The increasing fame of biofeedback game has brought convenience to human life. More and more people rely on biofeedback game as an alternative medical treatment to overcome their stress problems. GreenVec Biofeedback Game (GVBG) is a biofeedback game-based application that able to measure the skin conductivity of the player with an integration of Galvanic Skin Response (GSR) sensor. The measurement of the skin conductivity is crucial as an indicator for human meditation improvement in terms of stress control. In addition, GVBG spread awareness on global green technology issues, specifically about the Electric Vehicles (EV) topics to all users throughout the game process. The measured Skin Conductivity Level (SCL) corresponds to the player's awareness of the green EV through the GVBG Simulator. Furthermore, GVBGsimulates the biofeedback performance through the measured SCL. It creates a short report on the player's SCL based on the GSR sensor data and the game results at the end of the game session. From the results, the awareness on the EV is high when the SCL is high, whereas the awareness on the EV is low when the SCL is low. Therefore, GVBG Simulator helps users to train accordingly in order to reduce stress while at the same time gain awareness on the green technology issues with EV.
\end{abstract}

Keywords: GVBG; electric vehicles; GSR sensor; SCL, biofeedback simulator.

\section{INTRODUCTION}

Biofeedback has developed rapidly as an alternative medical treatment since it was discovered by researchers, meditators, and healthcare clinicians in the 1960s. The biofeedback terminology comes from two different root words; Bio and Feedback. Bio means life while feedback denotes giving back. Thus, biofeedback is the process of feeding back information about life responses. The Association for Applied Psychophysiology and Biofeedback (AAPB) and the International Society for Neurofeedback and Research (ISNR) defined biofeedback as "a process that enables an individual to learn how to change physiological activity for the purposes of improving health and performance"(AAPB, 2008, "What is Biofeedback," para.2). Biofeedback focuses on the control of diversity of bodily processes. Few common forms of biofeedback sensors are galvanic skin response (GSR), pulse sensors, temperature 
sensors and many more. By becoming aware of the ambiguous changes of the body, we can learn methods to control them and able to improve one's health. Nowadays, biofeedback game is highly demanded as an alternative cure to treat stress-related problems. In parallel with that, focus-training game is a game that emphasizes on the focus level of the players.

Green technology is a long-term solution which resolves problems in many aspects of life, including public transportation, reduces the dependency on petroleum and diesel in the country, lowering the amount of carbon emitted daily, free Malaysia from the problematic fuel subsidy issues and eventually saves the world from a worsen climate change ("Green Technology: Accelerating a sustainable transportation system," 2012). More importantly, Electric Vehicles (EVs) technology is part of the alternative of this green solution. EVs are propelled by an electrically operated motor powered by rechargeable battery packs. In other parts of the countries, demands for electric powered vehicles are increasing. For example, in Chicago, electrically operated garbage trucks are built by electric bus manufacturer called, Motive Power System to collect the garbage's in a garbage route provided. Another example can be seen in South Korea, where The Korea Advanced Institute of Science and Technology (KAIST),developed Online Electric Vehicles (OLEV) platform; an electric bus which plies a 15-mile route up to 10 times a day. In Malaysia, exposure is important to spread awareness on the right green technology concept, especially on the existence of EVs technology in their living environment. Only minorities of Malaysian are fully exposed to this newly introduced technology and its benefits towards a better future. With strong society in Malaysia, biofeedback game is reflected to many new generations (Biofeedback Lab, 2011). Due to its popularity, biofeedback game fits the purpose as a medium to expose the right EVs concept among the Malaysian. Besides that, the biofeedback game also teaches player proper relaxation practices throughout the game process and consequently, improves their meditation techniques as a whole. Biofeedback may still consider "high-technology" therapy that may be used to engender a relaxation response, thus treating the stress response itself (H,Eva, 2011).

GreenVec Biofeedback Game (GVBG) is a biofeedback game which integrates Galvanic Skin Response (GSR) sensor in its game. The game is based on the theme around University Malaysia Pahang. The player controls an electric car in a virtual track environment of University Malaysia Pahang. In this game, the player controls an electric car in a virtual track environment of University Malaysia Pahang. Player is required to avoid obstacles while moving approaching the end of the map. The car's life depends on its battery power, which is decreasing while moving. The faster the car speeds, the more battery power will be consumed. Player is required to collect the electric power in a form of a battery along their journey to maintain the car's life's span. The GSR sensor functions to measure human skin conductivity and provides an indication of changes in individual Sympathetic Nervous System (SNS) (Shi et al., 2007). Data collected through the skin conductance will be analyzed and be presented in a simple report at the end of the game. The report corresponds with the player's performance throughout the game.

This paper is organized as followed, Section 2 review the biofeedback manual system, existing systems and sensor technology. Section 3 elaborates the methodology of GVBG development. Section 4 presents the implementation of GVBG. Section 5 discusses the results. Finally, conclusions are presented in Section 5. 


\section{RELATED WORKS}

\section{MANUAL SYSTEM}

In a typical biofeedback session, a patient will be accompanied by a Biofeedback Therapist. The therapist usually approaches patient in a two-way conversation. The Biofeedback Therapist will require the patient to answer few questions related to theirlivesbackground. Occasionally, he or she helps the patient to remember things that the patient may have forgotten or understand patient's experiences in important new ways. At times, a patient may also be given a "paper and pencil" test to get additional helpful information. Then, the client settles in a comfortable recliner while the therapist begins cleaning patient's skin withexfoliate and alcohol. Next, the therapist guides patient through instructions by listening to their body's feedback ("Exactly what happens during the first Smarter Way Biofeedback Therapy Session?" 2012).

Another type of biofeedback session is where patients are attached with several electrical sensors by the therapist. These sensors functionedbymonitoringthe physiological state such as brain waves, skin temperature, muscle tension or heart rate variability of the patient. To observe changes in these physiological states, several techniques areincluded such as Electromyography (EMG) biofeedback thatspecifies information about body's muscles, Temperature (thermal) biofeedback which measure skin temperature, Galvanic Skin Response Training helpsto compute the sweat glands activity, and hears rate variability biofeedback which assistin controlling heart rate ("Biofeedback; What can you expect", 2010).

\section{EXISTING SYSTEMS}

Journey to Wild Divine, Relax to Win Game, Mind Balance Game, and emWave Desktop Stress Relief System are the current existing biofeedback games. Journey to Wild Divine is a biofeedback video game system promoting stress management and overall wellness through meditation, relaxation exercises, and mindfulness training. Founded by Kurt R. Smith and Corwin Bell in 2001, The Journey to Wild Divine is widely spread and highly rated as the world's best computer program for stress relief and stressed related health issues. On top of its biofeedback method as an alternative healthcare, this system also have a unique game concept, where players are allowed to use thoughts, emotions, and breathing to complete the mind and body training events (Wild Divine Inc, 2012).

Relax to Win game is a game developed by MIT Media Lab in the US (MarjaanaLehtinen, 2012). It is a game in a form of a race between two dragons. The Relax to Win, implements a competitive game structure where two players have to relax to determine the speed of the dragon. In a race against stress, the winner is the player who manages to relax the most during the course of the game ("Relax to Win - A New Game for Mobile Phone", 2006). Competitive games usually bringplayers to a certain level of increased tension, but in Relax to Win, player must discover to override this tendency, learn not only to relax, but to relax in a stressful environment ("Relax to Win - A New Game for Mobile Phone", 2006). The game takes place in a virtual 3D world set aboard a starship in space. The environment is designed to immerse the player and attract their attention to make the feedback process is more effective ("Video Games to Help You Relax", 2002). This is due to a fact that people's focus and adaptability level 
varieswith each other, thus an impressive environment is designedto effectivelyaffect player's attention.

Mind Balance was the first application developed by the MindGames group as part of ambitious collaboration with researchers at University College Dublin to implement new brain-computer control interfaces. The game concept is easy where a participant must assist a tightrope-walking behemoth known as the Mawg, by helping him balance as he totters across a cosmic tightrope ("Mind Balance"). There is no joystick, any mouse and not even a camera, but only a cap that non-invasively measures signals from the back of the head ("Mind Balance"). The cap which known as The Cerebus hardware device used for the game relies on an electroencephalogram (EEG) metric and the wireless technology Bluetooth to create a control mechanism. Instead of measuring the ratio between alpha and beta waves, The Cerebus monitors the occipital lobes at the back of the head to detect artifacts from the electrical signals produced by the brain's visual processing ("Cross-Country Olympic Mind Games"). Figure 1 shows the feedback loop of Mind Balance Game.

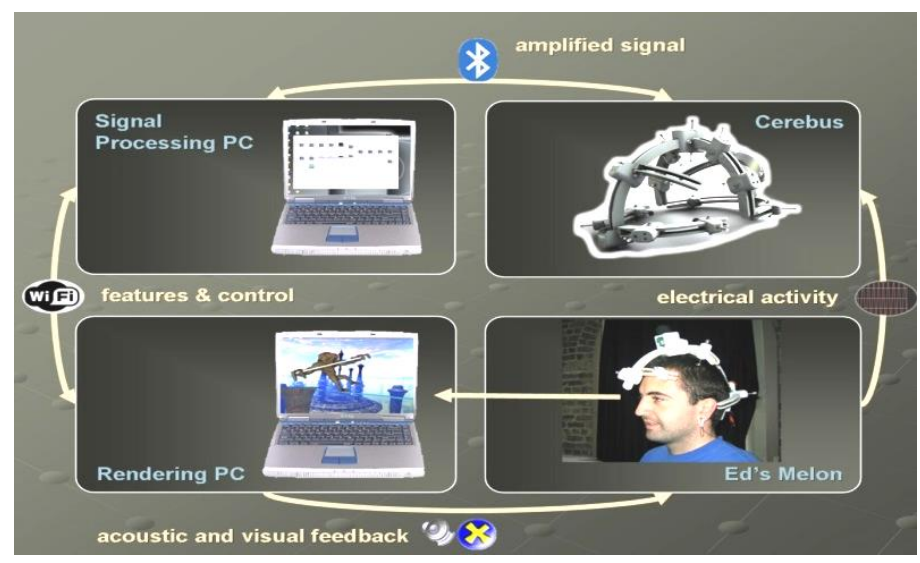

Figure 1. The feedback loop of Mind Balance Game

The emWave Desktop Stress Relief System is a scientifically validated software/hardware system that collects pulse data through an ear or finger sensor which plugs into your computer. Currently, this biofeedback instrument had been used and available at Biofeedback Lab at Gambang Campus, University Malaysia Pahang (UMP). The system translates the information from user heart rhythms into interactive graphics displayed on your monitor screen (IP Home LLC, 2011). The gameapproach offers four challenges level to help user sharpen their coherence building skills. Additionally, the system incorporates an accumulated coherence scoring display so you can track your progress during a session and save and review their sessions over time (Tools for Wellness, 2012). Basically, the emWave Desktop system determines the degree of coherence found in user's heart rhythm patterns and displays changes in real time. When stressed, user's heart rhythms will produce an incoherent pattern and vice versa. All of these changes of heart's rhythms patterns are displayed on the user's computer screen. By knowing the visual change on the screen and associating it with a more peaceful, calm internal state, user will be able to manage stress and maintain a state of physiological coherence and balance (IP Home LLC, 2011). Figure 2 shows the comparison of heart's rhythms pattern in a contrast coherence state. 


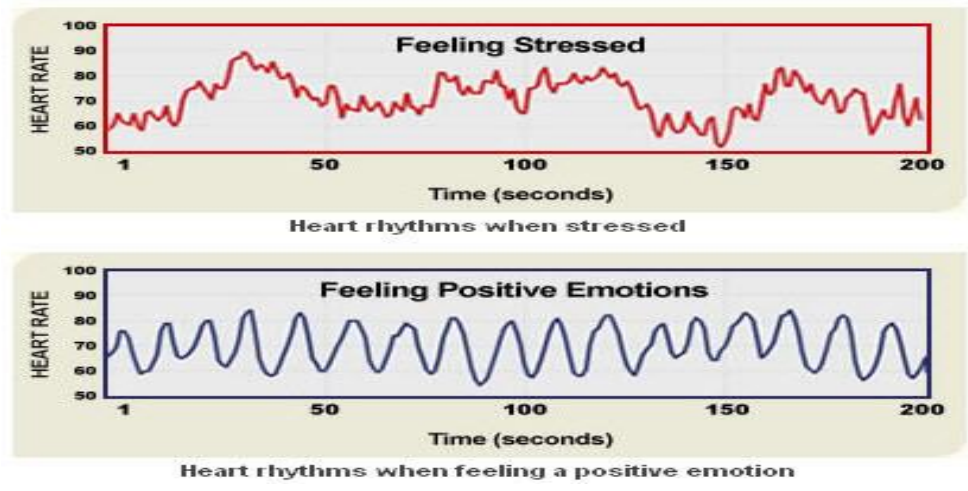

Figure 2. Comparison of Heart's Rhythms Patterns with emWave Desktop Stress Relief System

\section{SENSOR TECHNOLOGY}

Sensor is a device that detects and responds to some type of input from the physical environment. The specific input could be light, heat, motion, moisture, pressure, or any one of a great of other environmental phenomena. The output is generally a signal that is converted to human-readable display at the sensor location or transmitted electronically over a network for reading or further processing (W. Ivy, 2012).

Skin conductance or also known as Galvanic Skin Response (GSR) is one of the several electro dermal responses (EDRs). EDR changes in the electrical properties of a person's skin caused by an interaction between environmental events and the individual's psychological state ("The Galvanic Skin Response (GSR) and emotion"). The skin conductivity startles response is one of the most robust and well-studied physiologic responses (H. Jennifer, 1999) because skin conductance reflects more than one physiologic process due to its properties that change on the relatively short time scale of seconds. Skin conductance serves as indicators of processes as attention, habituation, arousal and cognitive effort in many different subdomains of psychology and related disciplines (Figner. B \& Murphy, R.O). Basically, skin conductance can be divided into two types; tonic and phasic skin conductance. Tonic skin conductance is the baseline level of skin conductance, in the absence of any particular discrete environmental event, and is generally referred to as Skin Conductance Level (SCL). Tonic skin conductance levels vary over time in individuals depending on his or her psychological state and autonomic regulation ("The Galvanic Skin Response (GSR) and emotion"). Another type of skin conductance is Phasic skin conductance, which changes when the events take place. Discrete environmental stimuli will evoke time-related changes in skin conductance. These are generally referred as Skin Conductance Responses (SCRs) ("The Galvanic Skin Response (GSR) and emotion").

Commonly, skin conductance reactivity is monitored using the feedback instrument such as Galvanic Skin Response (GSR) sensors. GSR sensor has two built in electrodes, which will automatically send the small electric andpass it through the body of the test subject to measure conductivity. The GSR reflects sweat gland activity and changes in the sympathetic nervous system and measurement variables. The measurement is taken from the subject's fingertips, where changes are monitored in the relative conductance of small electrical flow between the electrodes. The activity of the sweat glands in response to sympathetic nervous simulation (increased sympathetic 
activation) results to an increase in the level of conductance. There is a relationship between sympathetic activity and emotional arousal, although one cannot identify the specific emotion being elicited (F.D. George, 1977). While it is well correlated with emotional events in studies, the skin conductance response is still not entirely predictable.

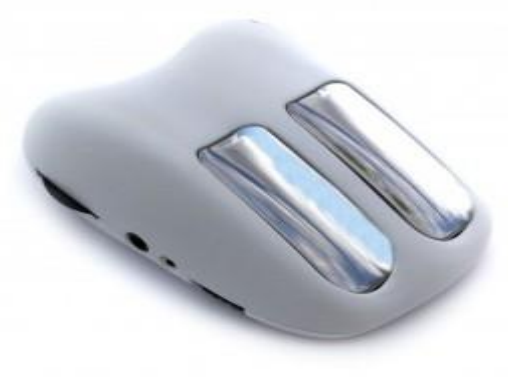

Figure 3. A GSR Sensor

Figure 3 shows the Galvanic Skin Response (GSR) Sensor to measure the skin conductivity level of a person. The measurement is based on the amount of current that can pass through our body. The GSR sensor shows how easy (conductance) or how difficult (resistance) it is for the current to pass through our body, and this is based on Ohm's Law. Ohm's Law states that the electric current flowing through a conductor is always proportional to the applied potential difference to it (voltage) but indirectly proportional to resistance value (Basic Electronics, 2011).

\section{METHODOLOGY}

During the development, Spiral Methodology is applied for smoother and clearer development processes. Figure 4 shows the Spiral Model as a whole. The Spiral Methodology involves iteration processes, which starts at a center of the spiral and continuously loop until customer's requirements are satisfied. There are six phases exist in the Spiral Methodology starting from Customer Communication, Planning, Risk Analysis, Engineering, Construction and Release, and lastly Customer Evaluation(W, B, Barry. 2003).

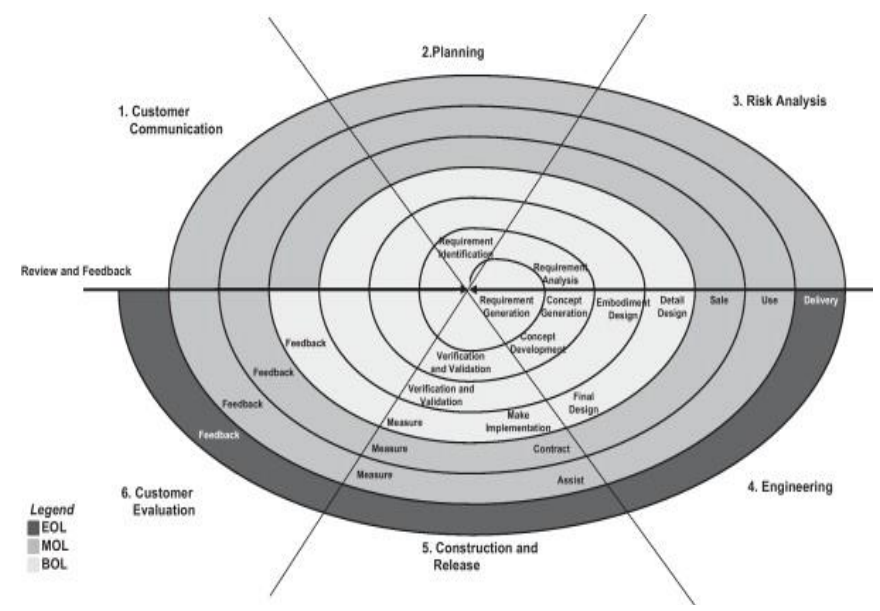

Figure 4. Spiral Methodology 
Spiral Methodology is an iterative life cycle model which is suitable for large, expensive, and complicated models. Although, Integrated GreenVec Biofeedback Game (IGVBG) using GSR sensor is not a large or expensive system yet it is truly complicated in its development processes. Plus, the integration of this biofeedback game with the external device which is the Galvanic Skin Response (GSR) sensor makes it to be more complex for data analysis and design phases.

For GVBG, repetitive validation and verification from the customer is essential to get accurate requirements during the design and data analysis phases. Inaccurate data gathered may affect the product's functionality critically. Besides that, Spiral Methodology is also capable inidentifying potential risk areas at the early stage of the processes. It has built-in critical features for risk mitigation and clarifying requirements. Risks are known as a main factor for high product costing. For GVBG, this is truly helpful because if the risk is accessed regularly, hence better planning can be made, and more cost can be saved. Without repetitive and risk mitigation features, the project development has higher possibility in costing by the end of the project.

The initial phase which is customer communication involves data collection of user requirement. This is usually done in a two-way conversation with the customer to discuss on the user requirements for the project development. This is a fundamental step of getting the accurate requirements to build the precise product for the customer. In this phase, close interview session was carried out with Assoc. Prof. Dr. Nubli, one of the biofeedback researchers in University Malaysia Pahang.

The second phase which is planning phase was done where all the needed resources are allocated, the milestones are well-planned, existing documentation has been done; objectives and constraints are determined, and others relevant information for a better understanding of GVBG using sensor are collected.

Figure 5 shows overall system flow design of GVBG.Before player enters the game, the GSR sensor must be connected to the player. The game starts when the player enters the Integrated GreenVec Biofeedback Games using GSR sensor. Firstly, the introduction video will be displayed at the beginning of the game. Then, player will be redirected to the home menu. Here, few options are available; player may choose to either access tutorial, access help menu or play the game. In tutorial site, player will be demonstrated with proper way of playing the game. Player will also be guided on how to achieve the game's goal. While in the help menu site only shows the keys for the GVBG game. When player enters the play game site, player will be redirected to the game environment. Here, all the game's score is kept into a database. A simple GSR raw data graph result is shown at the Relax Trace Program. Lastly, the GVBG using GSR sensor ends once player exit from the game.

\section{IMPLEMENTATION}

This section presents the implementation of GVBG. The following table lists the hardware requirements for the GVBG using GSR sensor development environment. The hardware requirements are divided into two separate categories, customer and developer's hardware requirements. The hardware requirements for GVBG using GSR sensor development are listed as followed:

A) For personal computer or notebook, the minimum hardware specifications are listed as below:

(a) At least $1.60 \mathrm{GHz}$ of Central Processing Unit (CPU)

(b) At least $512 \mathrm{MB}$ of Random Access Memory (RAM) 
(c) At least 256-color, minimal resolution 800 x600 display

(d) At least 5400 RPM hard disk

(e) Sound system with microphone input jack

(f) DVD-ROM with CD burner drive

(g) Universal Serial Bus (USB) port

(h) Built in Basic Graphics of $64 \mathrm{MB}$ that supports DirectX

B) For developer's desktop computer or notebook, the minimum hardware specifications are listed as below:

(a) At least $2.5 \mathrm{GHz}$ of Central Processing Unit (CPU)

(b) 64 bit of performance, $1024 \times 768$ resolution

(c) Sound system with microphone input jack

(d) At least $2048 \mathrm{MB}$ of RAM DDR3

(e) DVD-ROM with Multi Recorder

(f) Universal Serial Bus (USB) Port

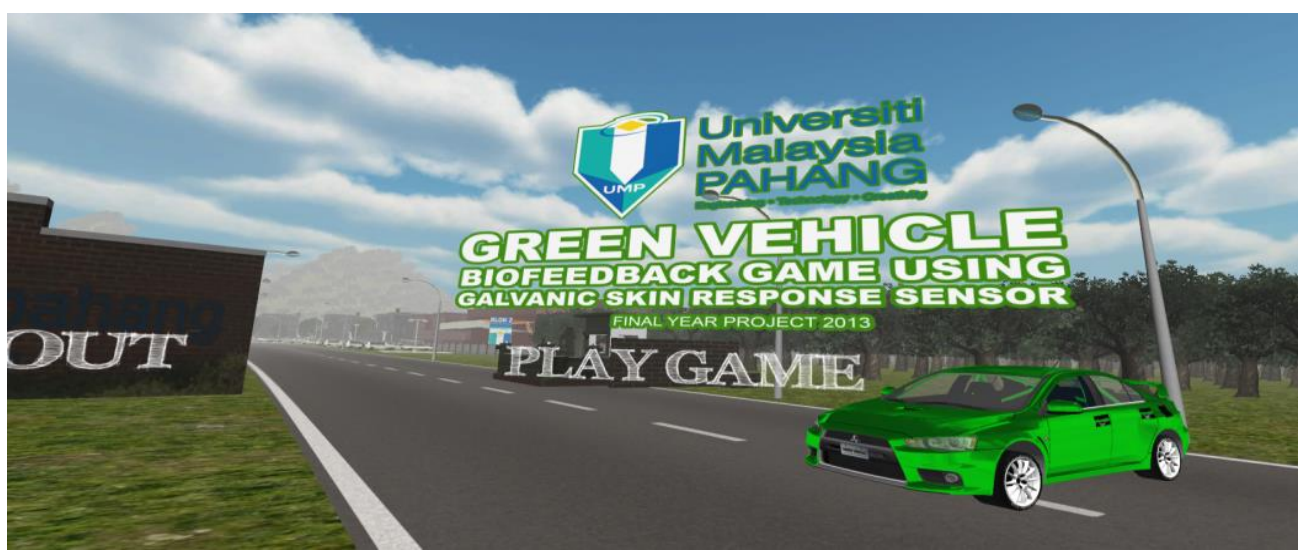

Figure 5. Main Menu of GVBG

The game interfaces are one of the essential elements of any game development, where it gives the initial impression of the game as a whole. The game interface should be attractive, simple, consistent and relevant with GVBG. Figure 5 shows the main interface of the game. When the player chooses to play the game, the user will be redirected to How to Play the Game as shown in Figure 6. This process only happens for first time user. For the second game and third game, player will be redirected straight to game area. In GVBG, database is vital to keep track of player's SCL biofeedback performance throughout the game session. Each of the players has unique profile, which was created by Biofeedback Trainer in command before the game started. GVBG database allows addition of new player. Each of players is also given their own web account for the game. Figure 7 shows the home page of the game database interfaces. Figure 8 shows the user profile of the player that consists of five sections. This section is compulsory if the minimum value from the EDR Trace from Relax Trace Application is positive and less than the baseline value. The third section is functioning as the Game Score Section where all the vital values; minimum values, maximum values, and baseline values from Relax Trace Application are collected. The fourth is the Graph Result Section. 


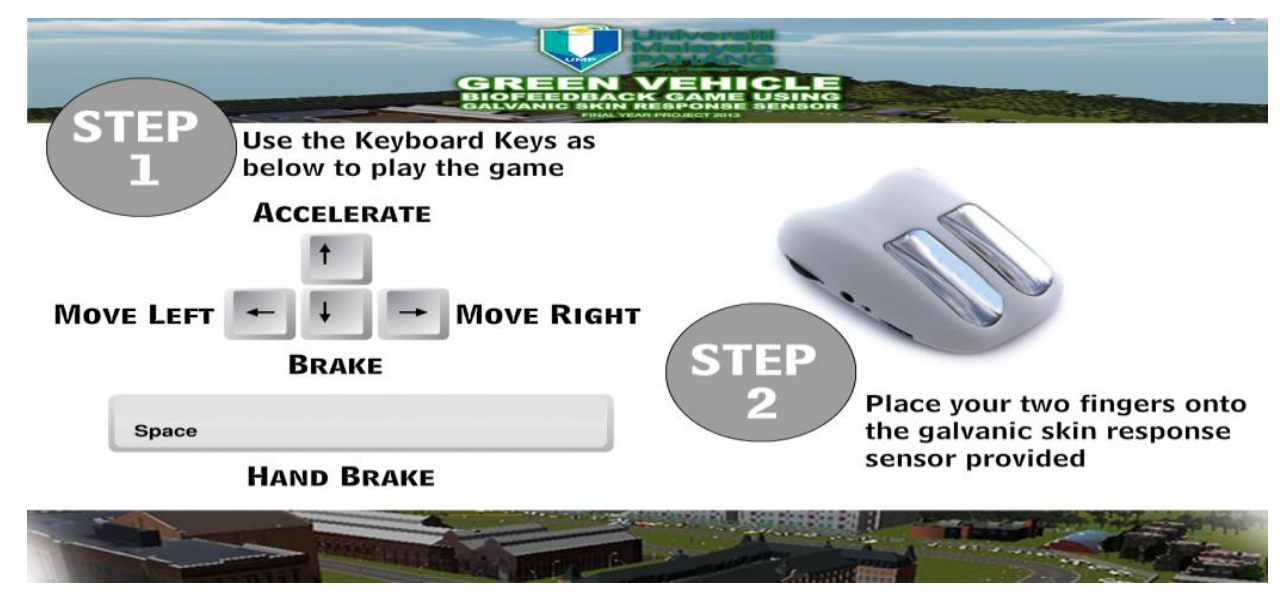

Figure 6. How to Play Section

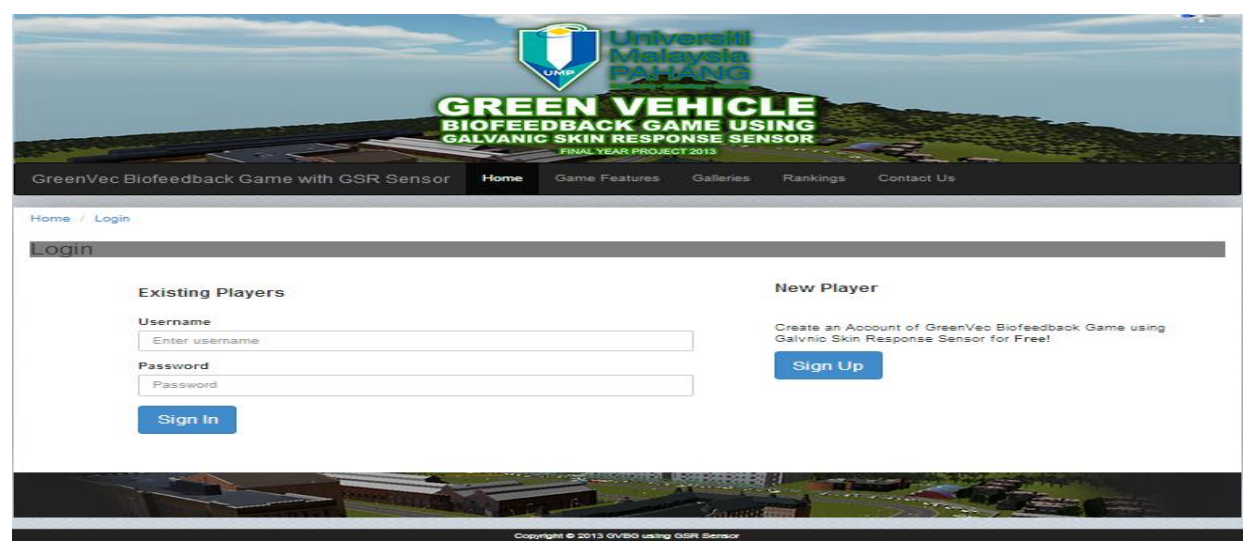

Figure 7. Homepage for GVBG database interface

This is the section that allows users to upload their graph's result, which was obtained from the Relax Trace Application. There are three graph results, and each of these graph results comes with their respective game score, which can be obtained from the exported Relax Trace Application data also. The fifth section is the most important section to generate the report summary of player's biofeedback performance. This section involves data analysis from all three game results and compiles them in into one simple report summary.

Figure 9 shows the EDR Trace detected using Relax Trace Application. The data was acquired when the players' two fingers in contact to the GSR device attached with the laptop. This EDR Trace will give an output for three values; minimum value, maximum value and baseline value. Minimum and maximum value is obtained from the raw signal data exported from the EDR Trace result while baseline value is the initial value of the EDR Trace in the graph when the button "Start Training" was clicked. Baseline value is unique for each player. For first-time user, it is compulsory to get the baseline value first before proceed with the real training session. 


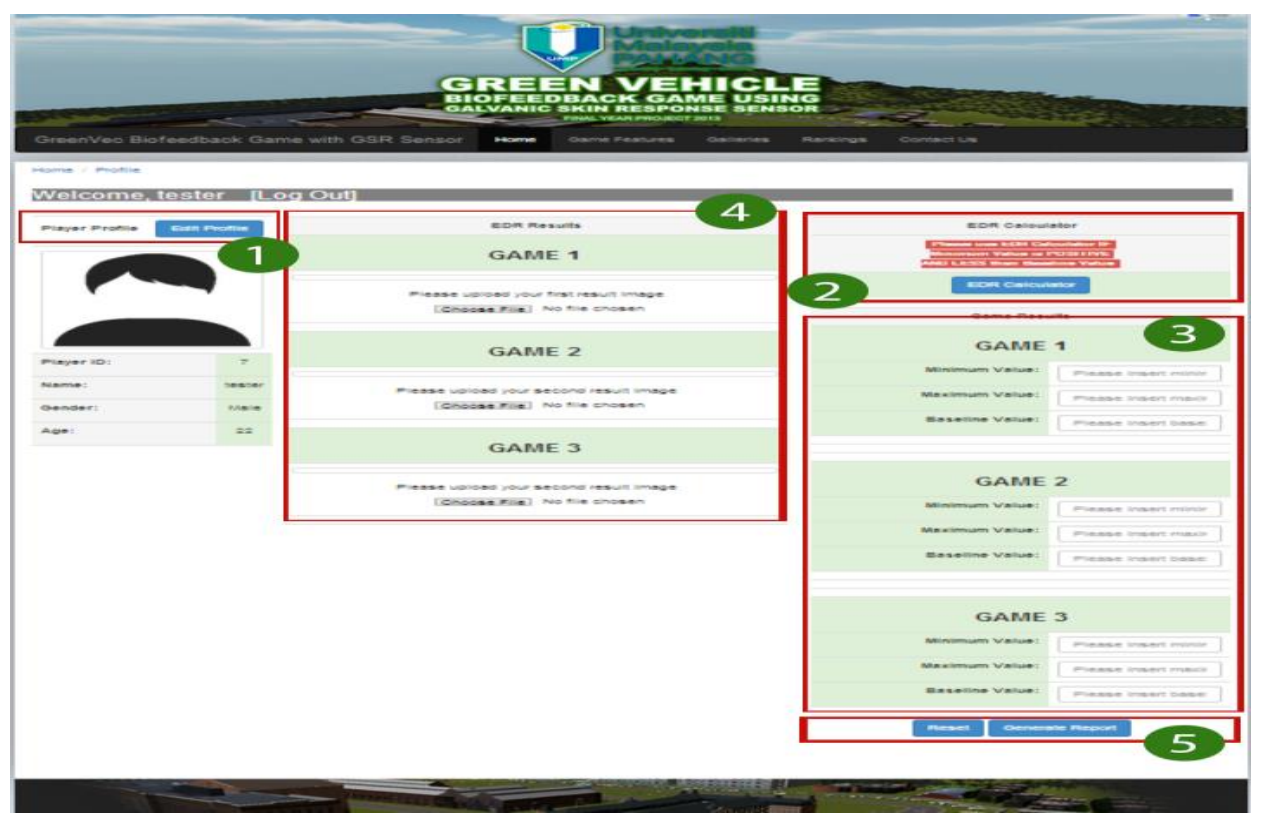

Figure 8. User Profile Page

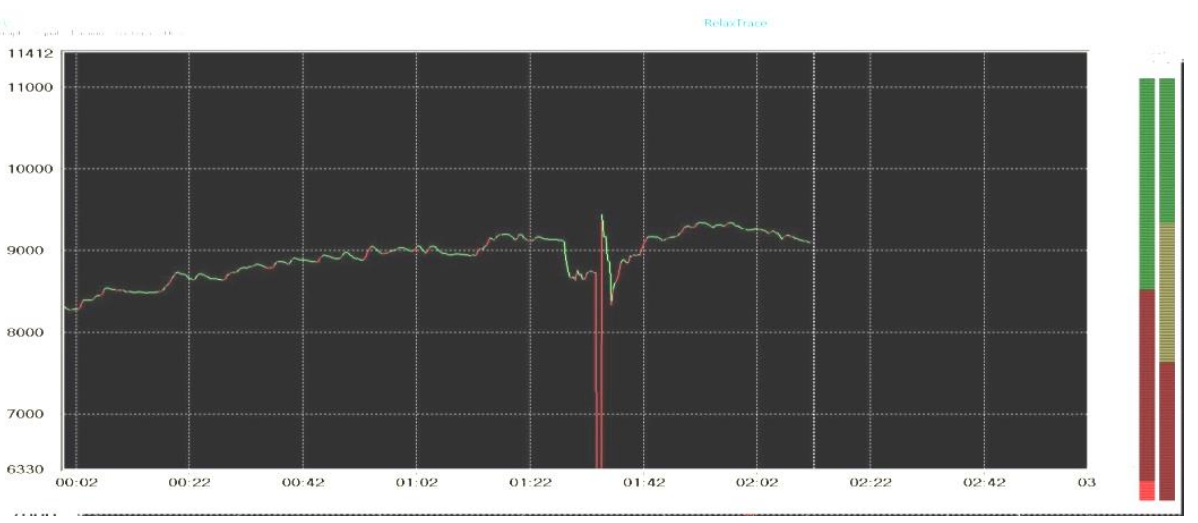

Figure 9. EDR Traces detected using Relax Trace Application

\section{RESULT AND DISCUSSION}

The results of SCL raw data was retrieved from Relax Trace application. Table 2-4 shows example results from GVBG Simulator.

Table 2. Awareness Level of EVs is high based on SCL of the Player

\begin{tabular}{lccc}
\hline \multicolumn{1}{c}{ SCL Data/Game Level } & Game 1 & Game 2 & Game 3 \\
\hline Minimum Value & $1204(\mathrm{~m})$ & $4570(\mathrm{~m})$ & $10341(\mathrm{~m})$ \\
\hline Maximum Value & $7556(\mathrm{~m})$ & $9860(\mathrm{~m})$ & $11057(\mathrm{~m})$ \\
\hline Awareness Level of EVs & & High & \\
\hline
\end{tabular}


Table 3. Awareness Level EVs is low based on SCL of the Player

\begin{tabular}{lccc}
\hline \multicolumn{1}{c}{ SCL Data/Game Level } & Game 1 & Game 2 & Game 3 \\
\hline Minimum Value & $-6307(\mathrm{~m})$ & $-3025(\mathrm{~m})$ & $6884(\mathrm{~m})$ \\
\hline Maximum Value & $5083(\mathrm{~m})$ & $2450(\mathrm{~m})$ & $7268(\mathrm{~m})$ \\
\hline \multicolumn{1}{c}{ Awareness Level of EVs } & & Low & \\
\hline
\end{tabular}

Table 4. Awareness Level EVs is balance based on SCL of the Player

\begin{tabular}{llcc}
\hline \multicolumn{1}{c}{ SCL Data/Game Level } & Game 1 & Game 2 & Game 3 \\
\hline Minimum Value & $-6000(\mathrm{~m})$ & $-6000(\mathrm{~m})$ & $-6000(\mathrm{~m})$ \\
\hline Maximum Value & $6000(\mathrm{~m})$ & $6000(\mathrm{~m})$ & $6000(\mathrm{~m})$ \\
\hline Awareness Level of EVs & & Balance & \\
\hline
\end{tabular}

Amplitude is measure in meter $(\mathrm{m})$. Below are the summarizations of the analysis for GSR data:

1. Amplitude f SCL is increased when the awareness of electric vehicles issues is high.

2. Amplitudeof SCL is decreased when the awareness of vehicles issues is low.

3. Amplitude of SCL is increased and decreased with balance when the awareness on vehicles issues is balanced.

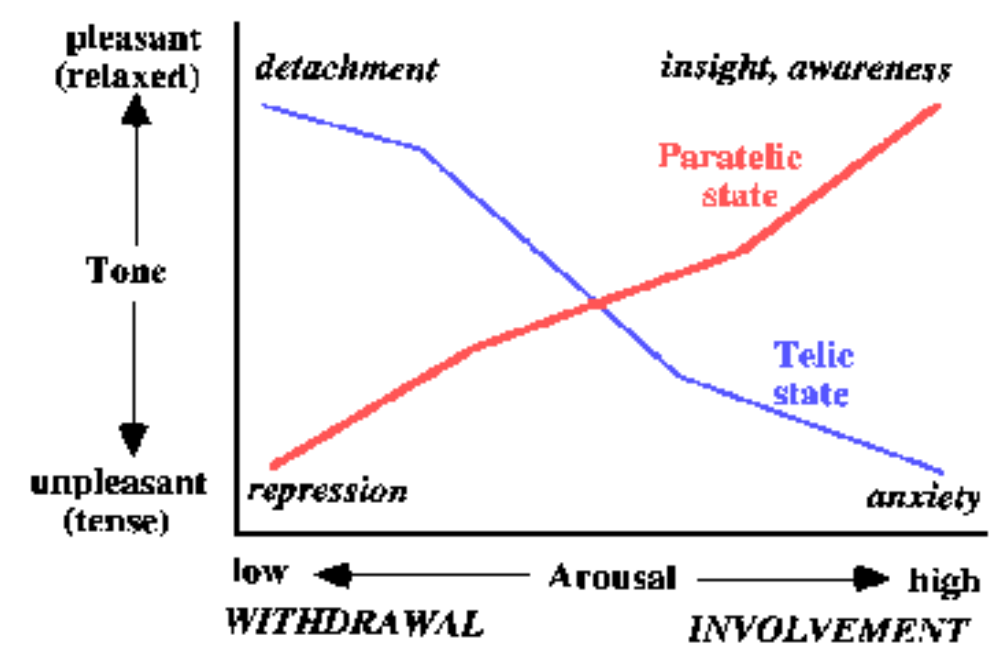

Figure 12. The Galvanic Skin Response (GSR) Meter Psycho-analytical research

GVBG using GSR Sensor has met all the objective of this project, which are:

1. To develop prototype of green vehicles biofeedback games using Galvanic Skin Response in order to give awareness about the Electric Vehicles (EVs) concept to the player

2. To measure the player's skin conductivity through this biofeedback game 
3. To generate a summary of the player's skin conductivity via this biofeedback game

\section{CONCLUSIONS}

GreenVec Biofeedback Game (GVBG) is software that put biofeedback technology and green technology together. The main intention behind this amalgamation is to bring awareness on Green Electric Vehicles (EVs) technology to Malaysian. Currently, knowledge on green technology particularly, Green Electric Vehicles among Malaysian citizen is considerably low and some of them even have misconception towards this environmental friendly technology. Thus, putting these two technologies together may be the best approach in promoting it. Mechanically, GVBG is integrated with the Galvanic Skin Response (GSR) sensor to measure the skin conductivity level of the player. This specific approach is implemented in order to discover the psychological phase of the player through biofeedback method. In addition, exposure to green vehicles concept is emphasized in the game with an objective that it could bring awareness to the player and could lessen the fuel consumption of a vehicles in the future. On top of that, SCL performance of each player is documented so that it can assist player in improving their psychological state into a better one. For future work, this SCL data can assist biofeedback researcher to further expand or create new method on how to cope with variety of psychological problems in today's society. The GVBG using GSR sensor is hoped to be a medium for pre-education knowledge exposure about the importance of Electric Vehicles (EVs) apart from being a newly meditation techniques for a better future in our society.

\section{ACKNOWLEDGEMENTS}

Appreciation conveyed to Ministry of Higher Education Malaysia for project financing under Fundamental Research Grant Scheme, RDU120119.

\section{REFERENCES}

Andreas Nilsson, Timothy L. Wilson, (2012) "Reflections on Barry W. Boehm's "A spiral model of software development and enhancement"", International Journal of Managing Projects in Business, Vol. 5 Iss: 4, pp. 737 - 756

A. Noraziah, M.N. Noorhuzaimi, S. Junaida. (2009). Smart Electronic Visitor Information Management System with Biometric Verification, Journal of Digital Information Management, Vol. 7, No. 5, pp. 318-322.

A.Noraziah, R Norhayati, AN Abdalla, AH Roslina, MA Noorlin, OM Affendy. (2008). A Novel Database System Model Design for Tender Management System, Journal of Computer Science, Vol. 4, No. 6, pp. 463-466.

Bersak, D., McDarby, G., Augenblick, N., McDarby, P., McDonnell, D., McDonald, B., \&Karkun, R. Intelligent Biofeedback using an Immersive Competitive Environment. Online Proceedings for the Designing Ubiquitous Computing Games Workshop (Atlanta GA, Sept 2001), available at: www.viktoria.se/play/workshops/ubigame.ubicomp

E, N, Lennart., K, Michael., L, Calvin., \& L, M, Regan: , "Biofeedback Game Design: Using Direct and Indirect Physiological Control to Enhance Game 
Interaction,"SIGCHI Conference on Human Factors in Computing Systems, vol., no., pp.103-112, 2011 doi: 10.1145/1978942.1978958.

H, Eva. (2011). Chapter 23 Affective Gaming in Education, Training, and Therapy: Motivation, Requirements, and Techniques. Retrieved from http://www.igiglobal.com/chapter/affective-gaming-education-training-therapy/52509.

JesperJuul: "The Game, the Player, the World: Looking for a Heart of Gameness". 81 In Level Up: Digital Games Research Conference Proceedings, edited by Marinka Copier and JoostRaessens, 30-45. Utrecht: Utrecht University, 2003

L, Marjaana. (2012). Bridging the gap between technology and human emotions. Retrieved from http://interface.tut.fi/articles/2012/1/Bridging_the_gap_between_technology_an d_human_emotions

Maricic, A.; Hiew Pang Leang;"Biofeedback computer game-based training," ELMAR, 2005. 47th International Symposium, vol., no., pp.185-188, 8-10 June 2005 doi: 10.1109/ELMAR.2005.193672.

Muhammad Nubli Abdul Wahab. (2011, October 20). Assoc. Prof. Dr. (S.A. Mohd Azrulnizam, Interviewer)

M.N. Noorhuzaimi @ Karimah, S. Junaida, A. Noraziah, K. Huei Chen. (2008). EVisitor Information Management System(E-VIMS) using MyKad, 1st IEEE International Conference On The Applications Of Digital Information And Web Technologies, IEEE Xplore, Czech Republic, Vol. 1, 44-49.

Noraziah, A., Ming, C., Wahab, M., Zin, N., Herawan, T., Leea, H., \&Abdalla, A. (2012). Integrated Environmental Protection Biofeedback Game (IEPBG) Using Galvanic Skin Response (GSR) Sensor.AWERProcedia Information Technology And Computer Science, Vol. 2, pp. 228-223.

N Ahmad, N Khan, ANA Alla, AH Beg. (2010). A Novel Database Design for Student Information System, Journal of Computer Science Vol. 6, No. 1, pp. 43-46.

W, B, Barry:, "A Spiral Model of Software Development and Enhancement." Computer, vol., no., pp.48-54, Sept 2003- Jan. 2004, Retrieved from weblog.erenkrantz.com/ jerenk/phase-ii/Boe88.pdf 